LUKA FILIPOVIĆ, istraživač-pripravnik

Institut za savremenu istoriju

Beograd, Republika Srbija

UDK 329.15(497.1:450)"1969"(093)

filipovic.luka95@gmail.com

$329.15(450) " 1969 "(093)$

originalan naučni rad / original scientific paper

primljeno / received: 31. 8. 2020.

prihvaćeno / accepted: 20. 11. 2020.

https://doi.org/10.29362/ist20veka.2021.1.fil.135-152

\title{
SAVEZ KOMUNISTA JUGOSLAVIJE I XII KONGRES KOMUNISTIČKE PARTIJE ITALIJE 1969. GODINE - POČECI TREĆEG PUTA SOCIJALIZMA U EVROPI
}

APSTRAKT: Formiranje ideologije evrokomunizma i evolucija odnosa koje je Jugoslavija imala sa komunističkim partijama Zapadne Evrope bili su kompleksni istorijski procesi dugog trajanja, u okviru kojih XII kongres Komunističke partije Italije (KPI) predstavlja samo jedan od prvih značajnih događaja. Članak pokušava da doprinese postavljanju geopolitičkih, društvenostrukturalnih i ideološko-teorijskih okvira ovog događaja. Rad je nastao prvenstveno na osnovu istraživanja arhivske građe Međunarodne komisije Centralnog komiteta Saveza komunista Jugoslavije (CK SKJ). Kroz analizu izveštaja CK razmatra se percepcija XII kongresa KPI od strane SKJ, dok analiza diplomatske prepiske i razgovora koji su vođeni tokom kongresa pomaže pri formiranju slike o trenutnim interesima SKJ i KPI. Komparacija ovih interesa kao i savremenih viđenja događaja koji su prethodili XII kongresu KPI služi boljem razumevanju okvira buduće izgradnje odnosa Jugoslavije i evrokomunističkih partija. Naposletku, u oblikovanju slike o geopolitičkim i društveno-istorijskim kontekstima ovih događaja korišćena je istorijska, sociološka i politikološka literatura nastala tokom prethodnih decenija.

KLJUČNE REČI: Evrokomunizam, Savez komunista Jugoslavije, Komunistička partija Italije, demokratski socijalizam, nova levica, Enriko Berlinguer

\section{„Cari Compagni“- \\ odnosi pre društvene i kulturne revolucije šezdesetih godina}

Odnosi Saveza komunista Jugoslavije i Komunističke partije Italije bili su uzdrmani jugoslovenskim raskolom sa Kominternom 1948. godine, kao i događajima u Jugoslaviji pedesetih godina. Kako pokazuje istraživanje Nikole Mijatova, KP Italije je u jugoslovenskoj percepciji vlastite geopolitičke pozicije bila samo jedan faktor heterogenog skupa evropskih komunističkih i socijalističkih partija sa kojima je Jugoslavija imala vrlo dinamične, ali nadasve turbu- 
lentne i fluktuidne odnose. ${ }^{1}$ „Slučaj Đilas“, unutrašnje strukturalne promene u društvu, ideologiji, spoljnoj politici i kulturi Jugoslavije, kao i sukob centralističke i decentralističke struje u okviru partijske hijerarhije u drugoj polovini pedesetih i prvoj polovini šezdesetih godina, dali su povoda evropskoj levici da ih tumači u skladu sa svojim trenutnim interesima. Prema globalnoj političkoj klimi i pragmatičnim ciljevima unutrašnje politike, ove promene bile su za evropske socijaliste ili znak progresa, demokratizacije, egalitarizacije i otvaranja jugoslovenskog socijalizma prema svetu, ili pak znak degradacije, totalitarizacije, boljševizacije i izolacionizma. Nekada su se ovi stavovi menjali veoma brzo, u toku jedne godine, ili čak jednog partijskog kongresa. ${ }^{2}$

Osim praktičnih ciljeva evropskih socijalističkih partija i njihovih unutrašnjih podela, bitan faktor ideološke „,nestabilnosti“ evropskog socijalizma u odnosu prema Jugoslaviji činili su različiti kulturološki, regionalni, etnički, religijski i društveni animoziteti koji su bili prikriveni imperativom uniformne ideologije. ${ }^{3}$ Upravo primer situacije u samoj Komunističkoj partiji Italije najbolje ilustruje mnogobrojne lokalne, istorijske, društvene i kulturološke razlike koje su u okvirima formalnih partijskih odnosa ${ }^{4}$ i projektovanih ideoloških formi mogle samo da se suptilno manifestuju u sporovima oko marginalnih pitanja, kao što je bilo pitanje odnosa prema Jugoslaviji pre šezdesetih godina.

Odnosi KPI i SKJ činili su samo deo veoma kompleksnih odnosa Italije i Jugoslavije. Mnogobrojni društveni i kulturološki faktori formirali su u očima jugoslovenskih savremenika veoma specifičnu percepciju Italije šezdesetih godina. ${ }^{5}$ Kako je istakao Predrag Marković, Italija je, sa svojim rapidnim privrednim, društvenim i političkim promenama, u kulturološko-antropološkom smislu za Jugoslovene bila idejni model ,slike o drugom“, odnosno u proširenom kontekstu, slike o zapadnom svetu. ${ }^{6} \mathrm{~S}$ druge strane, percepcija Jugoslavije u Italiji bila je uslovljena njenim veoma kompleksnim društvenim, kulturološkim i ideološkim strukturama, čije obrise sagledavamo i kroz mnogobrojne lokalne razlike i animozitete koji se javljaju u okviru naizgled uniformne ideologije KPI. ${ }^{7}$

Decentralistička kretanja u okviru KPI, međutim, mogla su da dođu do izražaja samo veoma suptilno, kroz podkontekste unutrašnjih sukoba u okviru iste ideološke doktrine. Na sličan način, i stavovi KP Italije o Jugoslaviji i, naročito, pravci njihovih promena izražavani su samo u uskoj sferi ograničenoj okvirima veoma formalizovanih i estetski uređenih obrazaca zvanične korespondencije.

\footnotetext{
${ }^{1}$ Nikola Mijatov, Milovan Đilas i evropski socijalisti (1950-1958) (Beograd: Institut za savremenu istoriju, 2019), 13-20.

${ }^{2}$ Isto, 101-139.

${ }^{3}$ Isto, 81-85.

${ }^{4}$ David Atlagić, prir., Luiđi Longo, Karlo Salinari - između reakcije i revolucije (Beograd: Izdavački centar Komunist, 1980), 656.

${ }^{5}$ Петар Драгишић, Шта смо знали о Италији? Погледи из Београда на Италију 1955-1978 (Београд: Институт за новију историју Србије, 2019), 41-59.

6 Predrag J. Marković, Trajnost i promena. Društvena istorija socijalističke svakodnevice $i$ postsvakodnevice u Jugoslaviji i Srbiji (Beograd: Službeni glasnik, 2011, drugo izdanje), 125-130.

${ }^{7}$ П. Драгишић, н. д., 114-129.
} 
Pisma i depeše koje Komunistička partija Italije upućuje Jugoslaviji od 1962. do 1968. godine puna su tradicionalne italijanske srdačnosti, stilskih figura i formalnih ideoloških fraza. ${ }^{8}$ Ispod toga, međutim, kriju se različita mišljenja i viđenja jugoslovenske pozicije, kako u bipolarnom tako i u komunističkom svetu, koja su bila promenljiva i turbulentna kao i partijske pozicije ličnosti i struja Luiđija Longa, Palmira Toljatija i Karla Salinarija. ${ }^{9}$

Vreme vakuuma u ideološkim i spoljnopolitičkim težnjama italijanske KPI, odnosno vreme ,između revolucije i demokratije“" ${ }^{10}$ poklapalo se sa vremenom velikih političkih, društvenih i kulturoloških promena u zapadnom svetu. Procesi pokrenuti nastankom države blagostanja (welfare state) dve decenije ranije izbili su na istorijsku površinu i postali vidljivi savremenicima u vidu onog što nam je danas poznato kao velika društvena i kulturna revolucija šezdesetih. $^{11} \mathrm{U}$ epilogu ovih strukturalnih promena sovjetski socijalistički model izgubio je primat kao društveno najprogresivnija leva ideologija na globalnom ideološkom tržištu. Novi liberalno-demokratski pokreti koji su iznikli iz velikih studentskih pobuna u SAD i Zapadnoj Evropi uveli su u ideološke percepcije savremenika nove ideje o demokratskom i institucionalnom rešavanju istorijskih problema društvenih nejednakosti, rasne, polne i ekonomske diskriminacije. ${ }^{12}$ Samo deceniju ranije, tokom čuvenog sukoba Sartra i Kamija, totalitarizam i revolucionarni teror bili su za najprogresivnije pariske intelektualce iz kruga Žan Pol Sartra i Simon de Bovoar „nužno zlo“ i „,cena“ koja se morala platiti zarad postizanja političke i pravne jednakosti i ekonomske sigurnosti za većinu stanovništva zapadnog sveta koja je pripadala upravo onim društvenim grupama koje su tek tada počinjale svoju dugu borbu za ljudska prava. ${ }^{13}$ Međutim, u toku samo jedne decenije nova frankfurtska škola društvene misli krenuće $u$,teorijsku potragu“ za nenasilnim, antiautoritarnim i inkluzivnim pandanom sovjetskom modelu revolucije, stvarajući začetke idejnih pravaca koji su nam danas poznati kao treći put socijalizma. ${ }^{14}$ Redakcija kejnzijanske formulacije države blagostanja, koju je dao engleski ekonomista Vilijam Beveridž, inicijalno osmišljena kao ,,privremeni kompromis“ koji treba da zaustavi „Crveno proleće" Evrope 1946. godine, postala je 20 godina kasnije ideološka alternativa sovjetskom modelu eksproprijacije i nacionalizacije. ${ }^{15}$ U geopolitičkoj ravnoteži snaga bipolarnog sveta koja nakon velikih kriza sa početka šezdesetih godina postaje sve stabilnija, SSSR je sve više prelazio u defanzivu i izolacionizam. „Bitka za duše“ Trećeg sveta bila je daleko od kraja, ali dve decenije američke

\footnotetext{
${ }^{8}$ Arhiv Jugoslavije (AJ), fond 507, Centralni komitet Saveza komunista Jugoslavije (CK SKJ), Međunarodna komisija, Italija, 507-IX, 48/I-1-723.

${ }^{9}$ D. Atlagić, n. d., 269-285.

${ }^{10}$ Isto, 656-701.

${ }^{11}$ Dubravka Stojanović, Rađanje globalnog sveta 1880-2015 (Beograd: Udruženje za savremenu istoriju, 2015), 199-235.

${ }^{12}$ Isto, 281-283.

${ }^{13}$ Albert Camus, L'Homme révolté (Paris: Gallimard, 1951).

${ }^{14}$ Razmig Kešejan, Leva hemisfera (Beograd: Fakultet za medije i komunikacije, 2016), 53-74.

${ }^{15}$ D. Stojanović, n. d., 201-229.
} 
kulturne diplomatije već su davale rezultate u pogledu „containment“ politike prema sovjetskom uticaju u vakuumima moći koji su stvarani u paralelnim procesima dekolonizacije. ${ }^{16}$ Nova ,ideološka tržišta“ koja su nastajala u graničnim zonama bipolarnog sveta takođe su postala otvorena za levu alternativu sovjetskom i kineskom modelu socijalizma.

Sva ova pitanja, naročito ona vezana za kritiku sovjetske i kineske spoljne politike, razmatrana su na XII kongresu KP Italije 1969. godine. U diskusijama o rekonstrukciji KPI u kojima su uzeli učešća i predstavnici jugoslovenske delegacije odlučeno je da će naslednik Luiđija Longa na mestu generalnog sekretara postati Enriko Berlinguer ${ }^{17}$ koji je godinu dana ranije došao u centar pažnje globalnih socijalističkih krugova zbog svoje kritike sovjetske agresije prema Čehoslovačkoj. Istovremeno, Berlinguer je stao na stranu SSSRa u sovjetsko-kineskom sukobu, napadajući kineski socijalistički model kao i kineske „hegemonske“ ambicije prema jugoistočnoj Aziji. ${ }^{18}$ Te akcije Enrika Berlinguera iz 1968. i 1969. godine predstavljaće prve primere buduće „srednje linije" koji su evrokomunističke partije zauzele prema geopolitici bipolarnog sveta, kao i kritičkog odnosa prema sovjetskom i kineskom totalitarizmu.

Spoljnopolitički interesi Jugoslavije kao i ideološke pozicije SKJ u ovom pogledu poklapali su se sa novim pravcima praktičnog i ideološkog kretanja KPI iznetim na XII kongresu februara 1969. godine. ${ }^{19}$ Jugoslovenska delegacija je vodila nekoliko serija individualnih razgovora sa vodećim ličnostima italijanske komunističke partije u kojima su razmatrani pravci buduće saradnje i zajedničkog delovanja u sferi ,globalnog“ socijalizma, naročito u pogledu formiranja zajedničkog stava prema politici SSSR-a i Kine. ${ }^{20}$ Jugoslovenski model samoupravnog socijalizma razmatran je u sesijama XII kongresa kao jedan od idejnih modela izgradnje trećeg puta socijalizma. Naposletku, razmatrana su pitanja naučne i medijske saradnje, uzajamne finansijske pomoći kao i odnosa sa ostalim komunističkim i socijalističkim partijama Evrope. ${ }^{21}$

\section{Pripreme jugoslovenske delegacije i promene u politici Komunističke partije Italije}

Tokom priprema za odlazak delegacije Jugoslavije na XII kongres italijanske komunističke partije CK SKJ je razmatrao opširan izveštaj o novim ideološkim stavovima i kretanjima u KPI. U izveštaju od 8. januara 1969. prve četiri stranice posvećene su stavovima koje je KPI iznela tokom prethodne godine povodom krize u Čehoslovačkoj. Između veoma oštrih osuda izrečenih prema SSSR-u zbog vojne intervencije i događaja u Pragu 1968. godine, naročito je

${ }^{16}$ Radina Vučetić, Coca-Cola Socialism: Americanization of Yugoslav Culture in the Sixties (Budapest: Central European University Press, 2018), 1-24.

${ }^{17}$ AJ, 507-IX, 48/I-429, XII kongres KPI, Politička rezolucija i izbor novog rukovodstva.

${ }^{18}$ Richard Kindersley, In search of Eurocommunism (London: Palgrave Macmillan, 1981).

${ }^{19}$ AJ, 507-IX, 48/I-427, Neki značajni stavovi KP Italije.

${ }^{20}$ AJ, 507-IX, 48/I-429, Tretman delegacije SKJ.

${ }^{21}$ AJ, 507-IX, 48/I-429, Ocene XII kongresa KPI. 
interesantan stav KPI da su agresivna spoljna politika nove administracije Brežnjeva kao i novi talas izolacionizma i uvođenja represivnih mera u politički život Varšavskog bloka zapravo ,veliki korak unazad u odnosu na odluku Sovjetske vlade od 30. oktobra 1956. godine, kojom se izražava spremnost za prevazilaženje nasilja i grešaka koje su slabile jedinstvo socijalističkih država, itd...". ${ }^{22}$ Radi se o jednoj od mnogobrojnih reformi administracije Nikite Hruščova u toku programa destaljinizacije Istočnog bloka, koje su, između ostalog, za jedan od primarnih ciljeva imale upravo da sovjetski model učine prihvatljivijim levici na Zapadu.

U skladu sa progresivnim imperativima epohe društvene i kulturne revolucije šezdesetih, u okviru koje KPI pokušava da pronađe vlastiti ,treći put ${ }^{6 *} u$ socijalizam, akcije Sovjetskog Saveza u Čehoslovačkoj viđene su kao regresivan i represivan akt i, još važnije, kao takve su otvoreno kritikovane. ${ }^{23}$ Takođe, odluka sovjetske vlade od 30. oktobra 1956. usledila je kao odgovor na kritike koje su dolazile na račun sovjetske intervencije u Mađarskoj iste godine. Već tada, sovjetski socijalistički model počeo je da gubi podršku i među svojim najvatrenijim pristalicama u Evropi (na primer, čuveno ,skretanje“ francuskih intelektualaca ka maoizmu kao jedinoj dostupnoj alternativi socijalističkom modelu SSSR-a i formulacija teorije o ,seljačkom socijalizmu“ u Francuskoj). ${ }^{24}$ Komunističke i socijalističke partije (naročito severne Evrope) ${ }^{25}$ tada upućuju prve otvorene kritike totalitarizma i intervencionizma SSSR-a. Interesantno je da već sledeće godine Komunistička partija Italije na inicijativu Enrika Berlinguera prestaje da šalje mlade kadrove na školovanje u Sovjetski Savez. Ipak, tada je KPI oštro osuđivala svaki otvoren ispad protiv politike SSSR-a i izbacivala iz svojih redova kritičare intervencije u Mađarskoj kao „liberalne disidente“. Međutim, u novim istorijskim okolnostima, 1968. godine Komunistička partija Italije nakon samita u Flenumu zaključuje da je sovjetska intervencija u Čehoslovačkoj ,nedopustiva devijacija“ varšavskog sistema. ${ }^{26}$

U istom izveštaju CK SKJ zapaža se da KPI sve više govori o ,italijanskom putu“" u socijalizam. U tom trenutku, osnovna karakteristika prema kojoj se ovaj put definisao bila je ideja o ,prevazilaženju blokova“. Pitanje kako ovo izvesti u praksi nije bilo još uvek razmatrano i Centralni komitet ocenjuje da ni među „dragim italijanskim drugovima“ još nema konsenzusa o ovom pitanju. Takođe, KPI ističe još dve bitne stavke pod tačkom ,italijanskog puta u socijalizam“ za predstojeći kongres - imperativ stvaranja socijalizma u kome će kritika svakog, pa i klasičnog marksističko-lenjinističkog pristupa ideologiji biti dopuštena i dobrodošla, i imperativ stvaranja ,teorije o državi bez partije vodilje“, dakle teorijskog koncipiranja antiautoritarnog socijalizma. ${ }^{27}$ Naposletku,

\footnotetext{
${ }^{22}$ AJ, 507-IX, 48/I-427, Neki značajni stavovi KPI - Intervencija u Čehoslovačkoj.

${ }^{23}$ AJ, 507-IX, 48/I-429, Teze KPI za XII kongres.

${ }^{24}$ R. Kešejan, n. d., 134-138, 183-191.

${ }^{25} \mathrm{~N}$. Mijatov, $n . d ., 81-83$.

${ }^{26}$ AJ, 507-IX, 48/I-427, Neki značajni stavovi KPI.

${ }^{27}$ AJ, 507-IX, 48/I-427, Neki značajni stavovi KPI, Protiv ideje o ,partiji vodilji“.
} 
zapaža se da se KPI bavi praktičnim pitanjima reforme školstva i zdravstvenog sistema, kao i položaja radničke klase. Naročito značajan je planirani osvrt KPI na teoriju socijalističkog delanja u okvirima institucionalnog i parlamentarnog, demokratskog sistema, kao i na koncepciju „višepartijskog socijalizma“ ${ }^{28}$

U razgovoru od 14. januara 1969. dopisnik lista L'Unita Franko Patrone saopštava L. Soldiću, zameniku načelnika odeljenja za međunarodne veze CK SKJ, da su članovi direkcije KPI Pajeta i Galuci izrazili u ime partije želju da Edvard Kardelj bude u jugoslovenskoj delegaciji, kako bi na XII kongresu KPI govorio o prethodno istaknutim teorijskim pitanjima. Pajeta i Galuci su posredno izneli da ,jugoslovensko socijalističko iskustvo“ smatraju važnim delom socijalističke istorije i ideološko-društvene teorije, čije bolje upoznavanje može doprineti teorijskim koncepcijama novog , italijanskog puta“ $u$ socijalizam. ${ }^{29}$

U mnogim dokumentima Komisije za međunarodne odnose CK SKJ u januaru 1969. podvučeno je, često i bez velike važnosti za dalji tekst, da će XII kongres Komunističke partije Italije imati poseban značaj, jer će se na njemu ,iznova govoriti o mnogim pitanjima koja ponovo postaju aktuelna nakon intervencije SSSR-a u Čehoslovačkoj, prema kojoj je KPI izrazila oštru kritiku“, kako je to uobičajeno formulisano. ${ }^{30} \mathrm{Za}$ članove jugoslovenske delegacije izabrani su Edvard Kardelj, Nijaz Dizdarević, Ema Derosi, V. Bulatović i G. Vučinić. ${ }^{31}$ Komunistička partija Italije uputila je telegram zahvalnosti i dobrodošlice međunarodnoj komisiji CK SKJ 17. januara 1969, istog dana kada je delegacija stigla u Italiju. ${ }^{32}$

U svom izlaganju pred izvršnim komitetom SKJ Nijaz Dizdarević je istakao da „XII kongres italijanske Komunističke partije neće biti samo od prelomnog značaja za KPI, već i za sve komunističke partije Zapadne Evrope, naročito one koje se još kolebaju..." 33

Od 17. do 19. januara 1969. Kardelj se u Italiji sastao sa predsednikom republike Đuzepeom Saragatom, premijerom Marianom Rumorom, ministrom spoljnih poslova Pjetrom Nenijem i mnogobrojnim predstavnicima vlade. ${ }^{34} \mathrm{Ti}$ susreti svedoče da su za Jugoslaviju odnosi sa zvaničnim organima italijanske države bili primarniji nego sa KPI, kao i da vladajuća Demokratsko-hrišćanska partija nije iznela otvorene zamerke zbog prisustva jugoslovenske delegacije na najvećem posleratnom kongresu najbrojnije opozicione partije. Naprotiv, italijanske vlasti iskoristile su priliku da učvrste odnose sa Jugoslavijom. Jedan od faktora koji je na ovo bitno uticao jeste i činjenica da u tom trenutku demohrišćansko-socijalistička koalicija nije osećala naročitu pretnju od KPI, budući da upravo u drugoj polovini šezdesetih biračko telo Komunističke partije Italije

\footnotetext{
${ }^{28}$ AJ, 507-IX, 48/I-427, Neki značajni stavovi KPI, Italijanski put u socijalizam.

${ }^{29}$ AJ, 507-IX, 48/I-428.

${ }^{30}$ AJ, 507-IX, 48/I-427, Neki značajni stavovi KPI, Italijanski put u socijalizam.

${ }^{31}$ AJ, 507-IX, 48/I-429, Predlog sastava delegacije SKJ za XII kongres KPI.

${ }^{32}$ AJ, 507-IX, 48/I-429, Telegram KPI.

33 AJ, 507-IX, 48/I-429, Izlaganje N. Dizdarevića na izvršnom komitetu SKJ o XII kongresu KPI.

${ }^{34}$ AJ, 507-IX, 48/I-429, Zabeleška o razgovoru druga Kardelja sa predsednikom republike Saragatom, 16. februara 1969. u Rimu.
} 
znatno opada (sa $35-40 \%$ na manje od $25 \%$ glasova). To je bila posledica društvenih $\mathrm{i}$ istorijskih procesa dugog trajanja na koje italijanski komunisti nisu na vreme i adekvatno odgovorili. Međutim, nakon promena u politici KPI, odbacivanja Kominforma i boljševizma, dakle prvih koraka u ,zaokretu“ ka evrokomunizmu, KPI se ubrzo vraća na stare pozicije i već početkom sedamdesetih godina ostvaruje $30-35 \%$ podrške. $^{35}$

Kao što će to pokazati potonji razgovori dokumentovani $\mathrm{u}$ fondu međunarodne komisije CK SKJ, Kardelj je izrazio podjednaku formalnu srdačnost u razgovorima sa ministrom spoljnih poslova Nenijem, vođom socijalističke partije, kao i u razgovorima sa Berlinguerom i Longom. ${ }^{36}$ Ova činjenica stavljena u kontekst nedavnih velikih sukoba između Socijalističke i Komunističke partije u Italiji svedoči o tome da je jugoslovenska delegacija bila prevashodno vođena neposrednim državnim interesima, a tek nakon toga, interesima formiranja zajedničkog evropskog komunističkog fronta prema SSSR-u u budućnosti. Problemi o kojima se raspravljalo u razgovorima sa Nenijem - nacionalne manjine ostavljene izvan granica matične države nakon razgraničenja u Tršćanskoj krizi, mirovna politika u Evropi, carina i privredna saradnja ${ }^{37}$ - bili su od mnogo većeg značaja za jugoslovensku državu od pitanja planiranih za XII kongres KP Italije. ${ }^{38}$ Ova pitanja su se još uvek mahom smatrala unutrašnjim pitanjima KPI i nisu još dobila ,globalan“ značaj u očima savremenika, koji će imati u narednoj deceniji.

\section{Između Čehoslovačke i Vijetnama - putevi zbližavanja}

Dvanaesti kongres Komunističke partije Italije održan je u Bolonji od 8 . do 15. februara 1969. U Italiji i ,široj svetskoj javnosti“ postao je poznat kao „,kongres odgovora“, navodi se u izveštaju CK SKJ. Ovaj izveštaj je isticao međunarodni i istorijski značaj kongresa pre nego što je sam kongres i počeo. ${ }^{39}$ Odgovori se odnose na tri ključna pitanja: „Prvo, o odnosu KPI prema politici vlade levog centra i opštim nemirima u Italiji, drugo, o karakteru socijalističkog društva za koje se KPI zalaže, i treće, o stavu KPI prema SSSR-u i drugim socijalističkim zemljama nakon intervencije u ČSSR“. ${ }^{40}$ Kongresu je, ne računajući strane delegacije, prisustvovalo 813 delegata i s obzirom na način biranja delegata međunarodna komisija CK SKJ zaključuje da je KPI u tom trenutku imala oko 1,5 miliona članova. ${ }^{41}$ Kongres je počeo veoma dugim ali dosta formalnim i uopštenim referatom Luiđija Longa, nakon čega se pristupilo govorima i diskusijama.

\footnotetext{
${ }^{35}$ Statistika preuzeta iz: Roberto Sarti, "The Dissolution of the Italian Communist Party (1991)", In defence of Marxism (2011), https://www.marxist.com/the-dissolution-of-the-italiancommunist-party-1991.htm (pristupljeno 28. 7. 2020).

${ }^{36}$ AJ, 507-IX, 48/I-429.

${ }^{37}$ AJ, 507-IX, 48/I-429, Zabeleška o razgovoru druga Kardelja sa ministrom spoljnih poslova Nenijem, 18. februara 1969. g. u Rimu.

${ }^{38}$ AJ, 507-IX, 48/I-427.

${ }^{39}$ AJ, S507-IX, 48/I-429, Teze KPI za XII kongres. Predlozi KPI za politički zaokret.

40 AJ, 507-IX, 48/I-429, Teze KPI za XII kongres. Kriza današnjeg sveta i borba za mir i socijalizam.

${ }^{41}$ AJ, 507-IX, 48/I-429, XII kongres KPI, Sastav kongresa.
} 
Uprkos globalnom značaju koji se kongresu pridavao još pre nego što je počeo i koji su mu dala kasnija vremena, XII kongres Komunističke partije Italije samo je formalno prihvatio stavove i mišljenja koja su već odnela prevagu u KPI tokom prošle godine, ${ }^{42}$ i čija je ,,pobeda“ bila posledica istorijskih, društvenih i kulturoloških procesa u Italiji i svetu tokom prethodne decenije. O tome da su zaključci kongresa bili poznati i pre nego što su počele diskusije svedoči činjenica da se teze koje je KPI istakla pre početka kongresa ne razlikuju od zaključaka iz izveštaja o odlukama kongresa koji su delegati podneli CK SKJ. ${ }^{43}$

Prva teza XII kongresa KP Italije, „Kriza današnjeg sveta i borba za mir i socijalizam“, za Jugoslaviju je u tom trenutku bila najznačajnija tema, jer je u diskusijama koje su usledile definisana nova spoljna politika KPI. Gotovo cela početna teza, diskusija koja je usledila i zaključak koji je kongres doneo bili su posvećeni čehoslovačkoj krizi i ,vatrenom“ pojasu Pacifika. Italijanski komunisti su ponovili i proširili svoje pređašnje oštre kritike vojne intervencije SSSR-a u Čehoslovačkoj. Usledila je kritika kineske agresivne politike na indijskoj granici i američke agresije na Vijetnam. Stavovi KPI iskazani ovom prilikom u potpunosti su se poklapali sa stavovima SKJ, ocenjuje Međunarodna komisija CK SKJ. ${ }^{44}$ Govorilo se i o protestima i novim pokretima koje je kriza u Vijetnamu izazvala u SAD, iako o njima nije donesena konačna ocena. Delegati KPI izrazili su stav da u načelu podržavaju progresivan, antiautoritaran i antiimperijalistički karakter novih antiratnih pokreta u SAD, ali i da je ideološka agenda tih pokreta previše heterogena i dezintegrisana da bi se o njoj mogao donositi sud. Takođe, izražena su strahovanja povodom pojave anarhističkih, liberalnih i kapitalističkih elemenata u ovim pokretima. ${ }^{45}$ Dok je kritika angažmana SAD u Vijetnamu bila podrazumevana, formalna i gotovo „ritualna“ $u$ savremenim govorima na kongresima komunističkih partija Evrope i sveta, pažnju je privuklo izražavanje solidarnosti sa ,indijskim narodom i narodima Indo-Kine“ prema kojima je „Kina izvela imperijalističku agresiju, prekršivši time sve principe socijalističke etike“. U sukobu SSSR-a i Kine KPI je podržala SSSR. ${ }^{46}$

Zaključak ove tačke počinje kritikom oba bloka bipolarnog sveta i obe dominantne globalne ideologije. Naročito se podvlači stav o izraženosti društvenih nejednakosti i različitih oblika diskriminacije u svetu zapadnog kapitalizma. Totalitarni režimi na Istoku koji sebe nazivaju socijalističkim i komunističkim nisu učinili mnogo u prevazilaženju ovih problema nakon prvih revolucionarnih uspeha, koji su se brzo pretvarali u revolucionarne terore. KP Italije, kako se zaključuje, mora naći svoj put između kapitalizma i totalitarizma, a za taj poduhvat biće potrebno mnogo teorijskog i praktičnog napora. Taj put se još

\footnotetext{
42 Саша Мишић, „Југословенско-италијански односи и чехословачка криза 1968. године“, у: 1968 - четрдесет година после, уредила Радмила Радић (Београд: Институт за новију историју Србије, 2008), 293-312.

${ }^{43}$ AJ, 507-IX, 48/I-429, Ocene XII kongresa KPI.

${ }^{44}$ AJ, 507-IX, 48/I-429, Teze KPI za XII kongres, Kriza današnjeg sveta i borba za mir i socijalizam.

${ }^{45}$ Isto.

${ }^{46}$ Isto.
} 
uvek ne definiše kao evrokomunizam niti kao „treći put“ socijalizma, prvenstveno zato što su ovi pojmovi tek kasnije ušli u svakodnevnu upotrebu ali ne i u zvaničnu terminologiju KPI. Takođe, naročita pažnja posvećuje se procesu dekolonizacije i razmatranju levih ideologija Trećeg sveta. Iskazuje se strahovanje da će te ,granične“ oblasti bipolarnog sveta postati meta ekonomskog imperijalizma i korporacijskog kolonijalizma, kao i da će nove države Trećeg sveta uprkos sticanju formalne nezavisnosti ostati pod kontrolom velikih imperijalnih sila. Pri razmatranju ovih pitanja kineski državni imperijalizam ne odvaja se od korporacijskog imperijalizma zapadnog sveta. ${ }^{47}$

U diskusiji o novoj međunarodnoj politici KPI ponavlja i proširuje pređašnju kritiku sovjetske agresije u Čehoslovačkoj. Upravo na ovom mestu dolazi do jedine prave debate koja je vođena u toku celog kongresa. ${ }^{48}$ Predstavnici pet zemalja Varšavskog pakta koji su prisustvovali kongresu (u tekstovima CK SKJ nazvani ,petorica“) digli su glas protiv ,prejake“ osude sovjetskih akcija u Čehoslovačkoj od strane KPI i održali govore u kojima su tvrdili da je intervencija SSSR-a bila neophodna ,kako bi se očuvao socijalistički poredak u ČSSR i samim tim mir u celom svetu“. ${ }^{49}$ Ova teza odmah je napadnuta od strane delegata KPI koji su tvrdili da socijalizam u ČSSR nije bio ugrožen i da je ,potpuno apsurdno misliti da bi promena režima u ČSSR, i da je do nje došlo, mogla ugroziti globalni mir i poredak...". Nakon ovog formalnog ponavljanja stavova koji su tokom prošle godine već izrečeni u zvaničnim izjavama, govorio je predstavnik Čehoslovačke za koga CK SKJ ocenjuje da je bio ,vidno zaplašen i instruiran od strane petorice...“. Naime, čehoslovački predstavnik Erban je ,gotovo zamolio predstavnike drugih partija da se prestanu uzbuđivati zbog Čehoslovačke..." i posvetio ostatak svog izlaganja potvrđivanju stavova iznetih od strane ,petorice“. Nakon ovoga, kako to nalazi CK SKJ, predstavnici Varšavskog pakta ,pokušali su da prevedu raspravu o ČSSR na jezik diplomatisanja“. Međutim, protiv ovoga su ustali predstavnici komunističkih partija Rumunije, Belgije, Engleske, Japana i predstavnici SKJ. ${ }^{50}$

Kardelj je u govoru izrazio stav da SKJ podržava stavove KPI po ovom pitanju, ističući da se Jugoslavija zalaže za princip autonomije svakog naroda i svakog socijalističkog pokreta. Takođe, on je insistirao na tome da ,bez ovakve autonomije nema demokratskih odnosa među socijalističkim zemljama i pokretima“. Kardelj je izjavio da se SKJ protivi „ne samo vojnoj intervenciji u Čehoslovačkoj, već svim sličnim intervencijama, kao i doktrini ograničenog suvereniteta", nadovezujući se time na pitanja američkih i kineskih spoljnopolitičkih agresija, i na pitanja blokovskih podela koja su pokrenuli delegati KPI. ${ }^{51}$

Nakon Kardelja i predstavnika Britanije i Japana govorio je Santjago Kariljo u ime Komunističke partije Španije. Nadovezujući se na ideju o principu

\footnotetext{
${ }^{47}$ AJ, 507-IX, 48/I-429, Teze KPI za XII kongres, Socijalizam za koji se borimo.

${ }^{48}$ AJ, 507-IX, 48/I-429, XII kongres KPI. Istupanje stranih predstavnika.

${ }^{49}$ Isto.

${ }^{50}$ Isto.

${ }^{51}$ AJ, 507-IX, 48/I-429, XII kongres KPI. Istupanje stranih predstavnika, Izlaganje druga Kardelja.
} 
autonomije lokalnih socijalističkih pokreta, on je govorio o ,kulturi dogmatizma“ koja se ustalila ne samo u klasičnoj marksističko-lenjinističkoj ideologiji već i u celoj savremenoj evropskoj i globalnoj levici. Podržavajući princip ,autonomije naroda i autonomije pokreta“, Kariljo je istakao važnost principa individualne slobode misli i kritičkog mišljenja. ${ }^{52}$

\section{Italijanski put}

Sledeće tačke dnevnog reda odnosile su se na unutrašnju rekonstrukciju KPI i na teorijsko formulisanje ideoloških koncepcija koje su trebale da služe kao osnova najavljene buduće politike italijanskog puta u socijalizam. Rezolucija kojom je na posletku zaključen kongres fokusira se na tri ključne tačke, podvučene u dokumentima CK SKJ - ,Shvatanje miroljubive koegzistencije, koncepcija demokratskog puta napredovanja u socijalizam i linija za novi proleterski internacionalizam“. ${ }^{53} \mathrm{Za}$ Jugoslaviju su tada od najveće važnosti bile prva teza, u čijoj je razradi ponovljena kritika SSSR-a i Kine, kao i poslednja, u kojoj se KPI opredelila za oblike internacionalnog delovanja koji stoje u kontrastu sa sovjetskim izolacionizmom, i za stvaranje internacionalnih puteva socijalizma van blokovske podele. Međutim, „srednja tačka“, posvećena definisanju demokratskog socijalizma kao nove ideološke linije dobiće na važnosti tek u narednoj deceniji. $^{54}$

Ovde formulisan stav KPI o velikim protestima i pobunama šezdesetih godina u komparaciji sa novim stavom o Katoličkoj crkvi možda najbolje pokazuje obrise potonjih ideoloških postulata evrokomunizma odnosno demokratskog socijalizma. ${ }^{55} \mathrm{~S}$ jedne strane, KPI iskazuje veoma srčanu podršku svim delovima nove progresivne agende društvene i kulturne revolucije šezdesetih, naročito onim koji se tiču ljudskih prava. ${ }^{56}$ Međutim, KPI ovde takođe ukazuje na činjenicu da su mnoge nove identitetske agende liberalnih partija zanemarile klasni kontekst diskriminacije protiv koje se bore. ${ }^{57}$ Podržavajući ovu borbu, KPI insistira na tome da se pitanje ekonomskih i društvenih nejednakosti ne može posmatrati odvojeno od pitanja rasne, polne, verske i etničke nejednakosti i vice versa, te da su faktori koji dovode do onoga što bi moderna sociološka nauka nazvala ,akumulacijom hendikepa“ neraskidivo povezani. U istom paragrafu, KPI formalno osuđuje crkvu zbog negativnog stava prema progresivnoj političkoj agendi, ali podržava njene napore da delove ove agende prihvati u vlastitoj kulturološkoj i teološkoj redakciji. Takođe, KPI podržava napore dela sveštenstva da na lokalnom nivou promoviše vrednosti solidarnosti, tolerancije i humanosti, kao i svest o društvenim nejednakostima. ${ }^{58}$ Upravo će suptilna ideo-

\footnotetext{
${ }^{52}$ AJ, 507-IX, 48/I-429, XII kongres KPI. Istupanje stranih predstavnika.

${ }^{53}$ AJ, 507-IX, 48/I-429, XII kongres KPI. Politička rezolucija i izbor novog rukovodstva.

${ }^{54}$ Ernest Mandel, From Stalinism to Eurocommunism (London: Verso, 1978).

${ }^{55}$ Videti: П. Драгишић, н. д., 59-96.

${ }^{56}$ AJ, 507-IX, 48/I-429, Teze KPI za XII kongres, Izgradnja jedne alternative levom centru.

${ }^{57}$ AJ, 507-IX, 48/I-429, XII kongres KPI. Stavovi tzv. nove levice.

${ }^{58}$ AJ, 507-IX, 48/I-429, Teze KPI za XII kongres. Socijalizam za koji se borimo.
} 
loška linija iskazana $\mathrm{u}$ ova dva nova stava KPI predstavljati idejni model za buduće „umereno revolucionarno“, tolerantno i inkluzivno shvatanje „srednje linije“ trećeg puta socijalizma, karakteristično za epohu ,pozne“ države blagostanja u Evropi. ${ }^{59}$

Ove koncepcije upravo u svom kontrastu svedoče o ideološkim finesama i distinkcijama koje su italijanski put, a potom i evrokomunizam, definisale kao ideologiju koja se ne može svrstati ni u spektar tradicionalnog marksizmalenjinizma, ni „Nove levice“, ni novih demokratsko-liberalnih ili hipi pokreta koji su se na istorijskoj površini zapadnog sveta pojavili 1968. godine. Savremenici nisu mogli da precizno definišu taj novi ,pravac socijalizma“, a ni danas, sa istorijske distance od pola veka, nije moguće dati dovoljno preciznu teorijsku definiciju demokratskog socijalizma. Uprkos tome, poznati su nam osnovni principi demokratskog socijalizma - učešće u parlamentarnom poretku, institucionalna borba za socijalnu pravdu, antiimperijalistička, antikapitalistička i istovremeno antiautoritarna $i$ antitotalitarna politika, promovisanje individualne slobode kritičkog mišljenja naspram ideološkog dogmatizma klasične (sovjetske) redakcije marksističko-lenjinističke teorije, politička i društvena tolerancija, inkluzivan odnos prema progresivnim aspektima tradicije, poštovanje regionalnih, etničkih, verskih i kulturoloških posebnosti, itd. Ovo su ujedno bili i finalni teorijski zaključci XII kongresa Komunističke partije Italije. ${ }^{60}$ Koliko je ovakva teorijska koncepcija mogla biti primenjena u praksi, kao i koliko se sama KPI u narednim godinama držala ideoloških principa formulisanih u Bolonji 1969. godine - pitanje je koje treba da postane predmet budućih istorijskih i društvenih istraživanja.

Stavovi izneti na XII kongresu KPI često su poistovećivani sa stavovima „Nove levice“ u Evropi, kojima i jesu u izvesnom smislu bliski. Međutim, KPI je u okviru svoje rezolucije posvetila celo jedno poglavlje upravo kritici „Nove levice“. Stavovi „Nove levice“ u Evropi okarakterisani su na XII kongresu KPI kao „maksimalistički, ekstremistički i nerealni, [ciljevi] koji ne odgovaraju savremenim uslovima Italije“. Dalje, kompromis sa „Novom levicom“ bi „,nužno vodio KPI u izolaciju od ostalih radničkih i demokratskih partija, kao i od samog radništva i naroda...".61 Ipak, i pored oštre kritike iznete na XII kongresu, KPI će u narednim godinama izražavati solidarnost sa pokretima „Nove levice“" u pogledu angažmana oko onih pitanja koja su se uklapala u ideološki model koji su definisali ,principi fondamentali“ XII kongresa. ${ }^{62}$

U narednim paragrafima rezolucije XII kongresa razmatrani su koraci koje KPI planira da preduzme da bi svoju unutrašnju i spoljnopolitičku poziciju gradila u skladu sa ,italijanskim putem u socijalizam“. Na prvom mestu istaknuta je potreba za stvaranjem međunarodnog radničkog pokreta koji neće

\footnotetext{
${ }^{59}$ R. Kešejan, n. d., 19-53.

${ }^{60}$ AJ, 507-IX, 48/I-429, XII kongres KPI. Politička rezolucija i izbor novog rukovodstva.

${ }^{61}$ AJ, 507-IX, 48/I-429, XII kongres KPI. Stavovi tzv. nove levice.

${ }^{62}$ AJ, 507-IX, 48/I-429, XII kongres KPI. Politička rezolucija i izbor novog rukovodstva.
} 
biti pod uticajem Varšavskog pakta i Kine. ${ }^{63}$ U ovom kontekstu Jugoslavija je pomenuta kao primer zemlje koja je izgradila svoju jedinstvenu vrstu socijalizma nezavisno od Kominforma. Jugoslovensko samoupravljanje takođe je razmatrano na XII kongresu kao vid socijalističkog uređenja koji je ,prilagođen lokalnim potrebama, te prirodnim, istorijskim, geografskim i kulturološkim posebnostima regiona“ itd. ${ }^{64}$ Činjenica da KPI u razmatranju samoupravljanja ističe upravo ove faktore posledica je težnje za povezivanjem ideje o nezavisnom, ,italijanskom putu“ u socijalizam sa lokalnim problemima Italije koji su bili najzastupljeniji tokom diskusija i sa zaključkom iz finalne rezolucije: da novi put u socijalizam za koji se opredeli KPI mora biti definisan $u$ skladu sa ,lokalnim potrebama Italije, a ne sa ideološkim dogmama i interesima globalnih blokova“. 65

„Kongres je izabrao E. Berlinguera za zamenika generalnog sekretara partije, čime je konačno rešeno i pitanje naslednika L. Longa“, reči su pretposlednjeg paragrafa u dokumentu CK SKJ o zaključcima XII kongresa KPI. To je prvi put da se Berlinguer pominje u ovom dokumentu. Za razliku od Longa, Napolitana, Amendole i Ingraoa on nije održao drugu besedu na početku kongresa, niti je uzeo veliko učešće u diskusijama. Zaključci kongresa, međutim, potpuno se poklapaju sa ideološkom linijom koju je Berlinguer promovisao tokom prethodne godine. Nakon kongresa on se prvi sastao sa predstavnicima stranih delegacija, među kojima su bili i Jugosloveni. Dokumenti međunarodnih komisija CK SKJ svedoče o pažnji koju Berlinguer dobija posle kongresa od strane globalne i domaće javnosti. Berlinguerov dolazak na čelo KPI bio je postepen i suptilan, kao i razvoj njegove nove ideološke linije.

Zaključna razmatranja XII kongresa KPI završavaju se sledećim rečima: „...da bi naša partija tako mogla izvršiti svoju dužnost u borbi za demokratiju i socijalizam u Italiji““ ${ }^{66}$ KPI je, dakle, prešla dug istorijski put od pedesetih godina kada je u govorima Longa i Toljatija demokratija bila ,buržoaska koncepcija suprotstavljena socijalističkom duhu“.67 Upravo zbog veze koju će iduća decenija dati ovim pojmovima u ideološkim koncepcijama komunističkih partija Zapadne Evrope, XII kongres KPI, inicijalno organizovan radi kratkoročnih i pragmatičnih ciljeva unutrašnje rekonstrukcije partije i sticanja međunarodne podrške za stavove i akcije KPI povodom krize u Čehoslovačkoj, označen je kao istorijska prekretnica evropskog komunizma ka demokratskom socijalizmu.

\footnotetext{
${ }^{63}$ AJ, 507-IX, 48/I-429, Teze KPI za XII kongres. Novi putevi i oblici jedinstva međunarodnog radničkog pokreta.

${ }^{64}$ AJ, 507-IX, 48/I-429, XII kongres KPI, Istupanje stranih predstavnika.

${ }^{65}$ AJ, 507-IX, 48/I-429, Teze KPI za XII kongres. Demokratija i jedinstvo partije.

${ }^{66}$ AJ, 507-IX, 48/I-429, XII kongres KPI. Politička rezolucija i izbor novog rukovodstva.

${ }^{67}$ AJ, 507-IX, 48/I-429, XII kongres KPI.
} 


\section{Jugoslovenska delegacija u Bolonji - razgovor Edvarda Kardelja i Luiđija Longa}

Delegacija SKJ je za vreme XII kongresa KPI imala mnogobrojne formalne i neformalne susrete i razgovore sa mnogim vodećim članovima Komunističke partije Italije. Đan Karlo Pajeta je dočekao delegaciju SKJ i igrao ulogu „domaćina“ i „,vodiča“ u danima boravka jugoslovenske delegacije u Bolonji. ${ }^{68}$ Izveštaji podneti CK SKJ svedoče da je ,posebna pažnja bila ukazana drugu Kardelju“ sa kojim su se pojedinačno sastali vodeći članovi KPI Napolitano, Amendola i Ingrao. Takođe, Kardelj se sastao sa predstavnicima delegacija drugih komunističkih partija, od kojih je u prvom redu pomenut njegov susret sa Santijagom Kariljom. ${ }^{69}$ Sa Berlinguerom Kardelj se sreo tokom prijema nakon kongresa, ali ovaj susret je za razliku od ostalih bio veoma kratak s obzirom na okolnosti ove svečanosti. Ipak, izveštaj međunarodne komisije nalazi za važno da napomene da je Kardelj sa Berlinguerom stigao da razgovara o dešavanjima na kongresu, spoljnopolitičkim pitanjima i situaciji u Međunarodnom komunističkom pokretu (MKP). ${ }^{70}$

De Valoria, sa kojim se Kardelj sastao prilikom prijema koji je za njega organizovan od strane KPI u zgradi bolonjske opštine, istakao je u srdačnom i šaljivom maniru da je „očigledno trebalo da drug Kardelj dođe u Italiju da bi Italijanska komunistička partija prihvatila tezu koju je SKJ iznela još pre 15 godina - da socijalizam ne prolazi samo preko socijalističkih granica, već da se on javlja u svim oblicima i svim sredinama širom sveta". ${ }^{71}$ Međutim, kada se stave na stranu izrazi „tradicionalne italijanske srdačnosti“ i formalni delovi razgovora, u toku prijema i razgovora sa De Valoriom faktički su samo ponovljeni zaključci iz rezolucije XII kongresa, koje su Kardelj i delegacija SKJ ponovno podržali. U neformalnim razgovorima sa delegatima KPI više se govorilo o ulozi jugoslovenske ideologije u sferi ,globalnog socijalizma“ i o uticaju ,jugoslovenskog puta" i jugoslovenskog raskida sa SSSR-om na buduće akcije KPI. ${ }^{72}$ Ipak, ovakve teze bile su mnogo više izrazi poštovanja i diplomatske kurtoazije prema delegaciji SKJ nego što su oslikavali stvarno stanje stvari. Komunistička partija Italije je odlučila da restrukturiše svoju ideologiju i spoljnu politiku zbog ugroženosti svojih neposrednih interesa u okviru same Italije, imperativa nove geopolitičke situacije i strukturalnih promena koje su se dešavale u zapadnom svetu krajem šezdesetih godina. „Slučaj Jugoslavije“ bio je samo ,istorijski primer“ izgradnje autonomnog socijalizma ${ }^{73}$ između granica blokovske podele sveta.

${ }^{68}$ AJ, 507-IX, 48/I-429, Tretman delegacije SKJ.

${ }^{69}$ AJ, 507-IX, 48/I-429, Kontakti sa predstavnicima inostranih delegacija.

${ }^{70}$ AJ, 507-IX, 48/I-429, Tretman delegacije SKJ.

${ }^{71}$ AJ, 507-IX, 48/I-429, Prilozi.

72 AJ, 507-IX, 48/I-429, Tretman delegacije SKJ.

73 AJ, 507-IX, 48/I-429, Teze KPI za XII kongres. Novi putevi i oblici jedinstva međunarodnog radničkog pokreta. 
Najznačajniji razgovor prilikom boravka jugoslovenske delegacije u Bolonji bio je razgovor Edvarda Kardelja sa generalnim sekretarom KPI Luiđijem Longom. Longo je sa članovima direkcije KPI Pajetom i Galucijem primio Kardelja i sekretara Izvršnog komiteta CK SKJ Miku Tripala 13. februara 1969. godine. Kardelj je na početku razgovora izjavio da je „,impresioniran“ radom kongresa, a naročito odlukama koje se odnose na zauzimanje novih spoljnopolitičkih stavova i na ,rekonstrukciju“ ideologije KPI. On je naročito istakao važnost činjenice da zemlje Varšavskog pakta nisu uspele da izvrše pritisak na članove drugih delegacija stranih komunističkih partija i da su ,,petorica“ ostala izolovana. „Ovo je činjenica koju SSSR neće moći da ignoriše“ zaključio je Kardelj. $^{74}$

Longo i Kardelj su se složili da je sovjetska akcija u Čehoslovačkoj vođena sa ciljem da zaustavi ,prelivanje“" progresivne političke agende na ,unutrašnjost" Sovjetskog Saveza, odnosno da predstavlja, kako je to Kardelj definisao, ofanzivu u defanzivi. Kardelj je, međutim, predočio i mogućnost da je to zapravo samo početak nove ofanzive SSSR-a prema socijalističkim zemljama koje nisu pod direktnim uticajem Moskve i izrazio spremnost Jugoslavije da se brani „Svim sredstvima“ ako SSSR pokaže ,agresivne tendencije“ ka njenim granicama. ${ }^{75}$ Da li je Kardelj stvarno verovao da je takav ishod moguć ili je tu mogućnost predstavio očekujući Longovu reakciju, za sada je nepoznato. Ipak, treba imati u vidu da savremenici čehoslovačke krize nisu mogli znati da SSSR nikada više neće preći u ofanzivu u globalnoj ,bici za duše“" (battle for the souls) i da će do kraja Hladnog rata ostati isključivo fokusiran na izolacionizam i odbranu svoje interesne sfere. Longo je u pogledu ovog pitanja bio dosta uzdržaniji od Kardelja. Sovjetska demonstracija moći u Čehoslovačkoj takođe služi prikrivanju duboke unutrašnje krize u kojoj se nalazi Varšavski pakt, ocenio je generalni sekretar KPI.

Longo je u razgovoru postavio mnogobrojna pitanja o odnosima Jugoslavije i drugih socijalističkih zemalja. Kardelj je naročito istakao dobre odnose Jugoslavije i Mađarske, ocenivši da je ,Mađarska, iako je učestvovala u intervenciji u Čehoslovačkoj, i dalje na stabilnom putu unutrašnjih reformi“. Longo je izrazio zahvalnost na poruci koju mu je uputio Josip Broz Tito nekoliko dana ranije, u kojoj je jugoslovenski predsednik pohvalio nove spoljnopolitičke stavove KPI i izrazio entuzijazam prema njenoj novoj ideološkoj liniji. Sledeća bitna tema bila je odluka Jugoslavije da ne učestvuje na samitu komunističkih partija u Moskvi. Kardelj je izjavio da je ova odluka definitivna, ali će „Jugoslavija podržati sve odluke koje budu u skladu sa vrednostima za koje se zalaže... itd.". Naravno, ovo je bila formalna diplomatska izjava. Svim učesnicima razgovora bilo je jasno da su odnosi Jugoslavije sa SSSR-om kao i sa Kinom trajno narušeni usled prethodnih događaja. Nakon ovoga pristupilo se razgovo-

\footnotetext{
${ }^{74}$ AJ, 507-IX, 48/I-429, Prilozi. Zabeleška o razgovoru Edvarda Kardelja sa Luiđi Longom, 13. II 1969. u Bolonji.

${ }^{75}$ Isto.
} 
rima o bilateralnim odnosima i formiranju zajedničkih naučnih grupa za izučavanje socijalističke teorije. $^{76}$

Tokom razgovora Kardelj i Longo su se uzdržavali od prejake osude „,petorice“. Ni u jednom trenutku nije rečeno da raskid sa SSSR-om može značiti okretanje Jugoslavije ili KPI ka Zapadu. Naprotiv, kako je razgovor odmicao, prema delegatima ,,petorice“ Kardelj i Longo su izražavali sve tolerantniji stav. Najznačajniju tačku razgovora predstavlja uzajamno slaganje o spremnosti za normalizaciju odnosa sa Varšavskim paktom čim do takve mogućnosti dođe. Takođe, Kardelj i Longo trudili su se da u izvesnom smislu opravdaju sve one postupke SSSR-a i Kine koji nisu bili u neposrednoj kontradikciji sa stavovima usvojenim na XII kongresu. To pokazuje da su i Jugoslavija i KPI u ovom trenutku sebe i dalje smatrali integralnim delovima socijalističkog sveta. Izražavajući u više navrata ,iskreno žaljenje zbog trenutnih neslaganja i grešaka naših drugova“, Kardelj i Longo zapravo su izražavali i dalje vrlo jako osećanje bliskosti svojih partija sa interesnom sferom SSSR-a. Činjenica da ,otklon prema Zapadu“ nije izgubio aktuelnost u nedavnim događajima bila je toliko očigledna da nije ni morala da bude jasno izrečena. U delu razgovora o spoljnopolitičkoj situaciji bilo je reči isključivo o pitanjima koja se tiču sfere ,socijalističkog sveta", a o sukobima unutar ove sfere govorilo se kao o lokalnim i unutrašnjim, a ne globalnim problemima. ${ }^{77}$

\section{Finalne ocene ,kongresa odgovora“"}

Evrokomunizam i demokratski socijalizam su, kao i sve ideologije 19. i 20. veka, morali imati koncept istorijskog porekla i ključnih događaja u prošlosti kojima se pripisuju posledice istorijskih procesa dugog trajanja. Savremenicima ovi događaji često nisu izgledali ni približno presudni kao što im je to pripisivala percepcija potonjih vremena. Neposredni i kratkoročni interesi socijalističkih partija diktirali su njihovo shvatanje aktuelnih događaja kao i njihovo ponašanje povodom njih. Tek će sledeća decenija, odnosno ,godine demokratskog socijalizma na Zapadu“, dati presudan i gotovo mitološki karakter XII kongresu KPI. S druge strane treba imati u vidu da je kongres, baveći se prevashodno spoljnopolitičkim pitanjima, u idejnom i teorijskom smislu dao samo faktičko priznanje onim ideološkim linijama i stavovima koje su već zauzimale dominantne struje unutar italijanske Komunističke partije. Procesi koji su doveli do toga da evrokomunizam postane novi dominantni ideološki obrazac levice u Zapadnoj Evropi pokazali su svoje spoljašnje manifestacije tokom XII kongresa Komunističke partije Italije.

Za Jugoslaviju su najznačajnije bile odluke XII kongresa koje su se odnosile na formulisanje nove spoljne politike KPI i na faktičko priznanje već ozvaničenog odstupanja Komunističke partije Italije od sovjetskog i kineskog socijalističkog modela. Činjenica da su Jugosloveni bili pozvani da na kongresu

\footnotetext{
${ }^{76}$ Isto.

${ }^{77}$ Isto.
} 
govore o svom istorijskom iskustvu otpora pritisku SSSR-a i o samoupravnom socijalizmu kao o sopstvenom putu izgradnje autonomnog socijalizma doprinela je povećanju interesovanja za jugoslovenski model i politiku nesvrstavanja u svetu „socijalističke hemisfere“. Bilateralni sporazumi i dogovori o naučnoj saradnji u okviru društvenih nauka i marksizma koji su sklopljeni tokom susreta sa predstavnicima KPI proširili su put jugoslovenskim teoretičarima na evropsko ,idejno“ tržište. Zajedničke akcije protiv „petorice“ kao i neformalni razgovori vođeni van kongresa doprineli su zbližavanju jugoslovenskih predstavnika sa delegacijama KP Španije, Britanije i Japana. 


\section{REFERENCE}

- Atlagić, David, prir. Luiđi Longo, Karlo Salinari - između reakcije i revolucije. Beograd: Izdavački centar Komunist, 1980.

- Berlinguer, Enrico. Letters to the Heretics: Correspondence with the Leaders of the New Italian Left. Milano: Ghiselli, 1977.

- Brend, Ivan T. Ekonomska istorija Evrope u XX veku. Beograd: Arhipelag, 2009.

- Camus, Albert. L'Homme révolté. Pari: Gallimard, 1951.

- Dragišić, Petar. Šta smo znali o Italiji? Pogledi iz Beograda na Italiju 19551978. Beograd: Institut za noviju istoriju Srbije, 2019.

- Kindersley, Richard. In search of Eurocommunism. London: Palgrave Macmillan, 1981. https://doi.org/10.1007/978-1-349-16581-0

- Mandel, Ernest. From Stalinism to Eurocommunism. London: Verso, 1978.

- Marković, Predrag. Trajnost i promena. Društvena istorija socijalističke svakodnevice i postsvakodnevice u Jugoslaviji i Srbiji. Beograd: Službeni glasnik, 2011.

- Mijatov, Nikola. Milovan Đilas i evropski socijalisti. Beograd: Institut za savremenu istoriju, 2020. https://doi.org/10.29362/2305.2019.mij

- Mišić, Saša. „Jugoslovensko-italijanski odnosi i Čehoslovačka kriza 1968. godine“. U: 1968 - četrdeset godina posle. Uredila Radmila Radić, 293-312. Beograd: Institut za noviju istoriju Srbije, 2008.

- Sarti, Roberto. "The Dissolution of the Italian Communist Party (1991)", In defence of Marxism (2011), https://www.marxist.com/the-dissolution-of-theitalian-communist-party-1991.htm (pristupljeno 28. 7. 2020).

- Stojanović, Dubravka. Rađanje globalnog sveta 1880-2015. Beograd: Udruženje za društvenu istoriju, 2015.

- Vučetić, Radina. Coca-Cola Socialism: Americanization of Yugoslav Culture in the Sixties. Budapest: Central European University Press, 2018. 
LUKA FILIPOVIĆ, Junior Research Assistant

Institute for Contemporary History

Belgrade, Republic of Serbia

filipovic.luka95@gmail.com

THE LEAGUE OF COMMUNISTS OF YUGOSLAVIA AND

THE XII CONGRESS OF THE COMMUNIST PARTY OF ITALY 1969 THE BEGINNINGS OF THE THIRD PATH OF SOCIALISM IN EUROPE

\section{Summary}

After the USSR had lost the global "battle for the souls" against the Western world in the global aftermath of the great social and cultural revolution of the sixties, its potential for international integration of the progressive, socialist and leftist ideologies of the world rapidly declined, which opened up an era of Soviet isolationism. Yet at the same time, new major, "players" arose on the stage of international socialism. Communist parties of Western Europe, primarily those of France, Italy, and Spain, completed under the welfare state era their two decades long process of ideological evolution toward what was to become known as Eurocommunism, and later as democratic socialism. In the aftermath of the great social and cultural revolution of the Western World during the sixties, and in the aftermath of its falling out with the USSR following the Soviet aggression against Czechoslovakia after the events of the Prague Spring, the Italian Communist Party called upon its deputies and delegations of the foreign communist parties to attend the XII Congress of P.I.C., which was supposed to determine the future positions of the party concerning international affairs and conduct the long-awaited reconstruction of the party's ideology, creating along the way the specific ideological line that was known among its contemporaries as the Italian path of socialism.

Yugoslavia had been one of the strongest supporters of the Italian path and of Italian criticism of the USSR. The Yugoslav delegation in Bologna conducted a series of talks with the Italian communist leaders and concluded a number of bilateral treaties with the Italian Communist Party. Also, the Yugoslav representatives used the occasion of their visit to strengthen relations with the representatives of the Italian Government. Sources show that Yugoslavia had started to take increasingly greater interest in the formation of the new European socialist ideologies, and the interest was apparently mutual, since the Yugoslav historical experience of breaking away from the Cominform two decades earlier and Yugoslav socialist ideas of self-government of the working class had been one of main topics in the discussions that held at the XII Congress regarding the ideas for the reconstruction of the Italian Communist Party, its foreign policies, and its ideology.

KEYWORDS: Eurocommunism, League of Communists of Yugoslavia, Communist Party of Italy, Democratic Socialism, New Left, Enrico Berlinguer 